\title{
Linking self-determined functional problems of patients with neck pain to the International Classification of Functioning, Disability, and Health (ICF)
}

\author{
This article was published in the following Dove Press journal: \\ Patient Preference and Adherence \\ 19 October 2012 \\ Number of times this article has been viewed
}

\author{
Nada Andelic' \\ Jan Borre Johansen' \\ Erik Bautz-Holter ${ }^{1,2}$ \\ Anne Marit Mengshoel ${ }^{3}$ \\ Eva Bakke 3 \\ Cecilie Roe ${ }^{1,2}$ \\ 'Department of Physical Medicine \\ and Rehabilitation, Oslo University \\ Hospital, Oslo, Norway; ${ }^{2}$ Faculty of \\ Medicine, University of Oslo, Oslo, \\ Norway; ${ }^{3}$ Department of Health \\ Sciences, Institute of Health and \\ Society, University of Oslo, Oslo, \\ Norway
}

Objective: To describe commonly reported self-determined functional problems in patients with neck pain and to evaluate their fit to the components of the International Classification of Functioning, Disability, and Health (ICF).

Methods: Overall, 249 patients were included in this cross-sectional study that comprised patients with neck pain referred to the outpatient clinic at Oslo University Hospital (2007-2009). Patients were asked to report their three most significant functional problems on the PatientSpecific Functional Scale, a self-determined measure of function. The ICF was used as a tool for analysis. Meaningful concepts within the functional problems were identified, coded, and linked to second-level categories within the components of "body functions," and "activities and participation." Two researchers performed coding and linking independently. The ICF categories were presented by percentage of the total number of functional problems linked to the ICF.

Results: Of 628 reported functional problems, 13 meaningful ICF domains were identified: four domains belonging to the body functions component (b) and nine domains belonging to activities and participation components (d). Within the 88 second-level ICF classification categories of body functions, the most frequently reported items were sleep function (b134; 27\%) and mobility of joint functions (b710; 26\%). Within the 538 second-level categories of activities and participation, remunerative employment was reported as the most frequent item (d850; 15\%), closely followed by doing housework (d640; 14\%), and recreation and leisure activities (d920; 13\%). Only two meaningful concepts, described as "be active" and "to function after activities," were not assigned to a specific ICF category.

Conclusion: The majority of the specific functional problems presented by patients in this study showed a good fit with the ICF model. The substantial number of links to the activities and participation categories, such as mobility, domestic life, employment, and social and civic life, suggests that a comprehensive approach, as well as the involvement of a multidisciplinary team, should be present in the rehabilitation of neck pain-related disability.

Keywords: neck pain disability, self-determined functional problems, PSFS, ICF

\section{Introduction}

Patients experiencing neck pain (ie, discomfort or more intense forms of pain that are localized to the posterior or lateral cervical region) $)^{1}$ constitute a large and heterogeneous group. ${ }^{2,3}$ Patients experiencing a chronic course of neck pain often have substantial functional limitations. ${ }^{4,5}$ These patients are often referred to specialist units, and they account for the majority of health care utilizations and costs. ${ }^{6}$
Correspondence: Nada Andelic Department of Physical Medicine and Rehabilitation, Oslo University Hospital PB 4950 Nydalen, 0424 Oslo, Norway Tel +4791817910

Email nandelic@online.no 
According to Barten et al, ${ }^{7}$ there has been an increase in patient-based concepts in health policy, and individualized outcome measures are becoming increasingly important. The patient's perspective in addressing neck pain-related functioning and disability may be an important part of the identification of and consensus about which aspects of functioning need to be addressed in the management of patients with neck pain. ${ }^{8}$ The Patient-Specific Functional Scale (PSFS), ${ }^{9}$ which is based on self-determined functional problems, is often used in clinical practice to assess patientfocused functional outcomes in musculoskeletal patients, including patients with neck disabilities. ${ }^{10}$ However, it is questionable to what extent the patient-specific outcomes are comparable between patients because of the individualized content. ${ }^{?}$

In rehabilitation medicine, it has become a common practice to classify the consequences of disease and to structure rehabilitation goals according to the International Classification of Functioning, Disability and Health (ICF), which is founded on the bio-psycho-social model of health. ${ }^{11}$ Conceptually, the ICF is based on an integrative model that covers functioning within the components: body functions (b), body structures (s), activities and participation (d), and contextual factors: environmental factors (e) and personal factors not classified in the ICF.

In a patient-oriented approach, the ICF model can help care providers to identify patients functioning and disability by using a standard language for the description of the ICF components. ${ }^{12}$ Fairbairn et $\mathrm{a}^{13}$ argued that outcome measures in clinical practice should reflect the ICF model to ensure that the assessments cover all aspects of daily life.

In a recently published review, ${ }^{14}$ some of the frequently used neck pain-specific questionnaires that measure functioning and disability and content-predetermined items were linked to the ICF. Within the body functions component, the sensation of pain, sleep disturbances, and respiratory dysfunctions were addressed as the most commonly measured ICF categories. Within the domain of activities and participation, the questionnaires were found to address participation in recreation, leisure, and work activities, and other activities of daily living including eating, dressing, self-washing, reading, and housework. ${ }^{14}$ However in practice, the evaluated questionnaires are often difficult to interpret on an individual level, as they do not address what the patient considers to be the significant problems related to the neck pain.

To our knowledge, only one study from New Zealand has classified the extent to which the patients' self-determined problems assessed by the PSFS reflects the ICF framework, in patients with musculoskeletal pain. ${ }^{13}$ The study found that the ICF component of activities and participation were more commonly represented in these patients than the body functions component.

There is increasing evidence that cultural factors seem to be important in neck pain-related disability. ${ }^{15}$ Thus, it can be argued that cross-cultural studies from different countries may provide a more accurate reflection of functional problems following neck pain, from both the global and patients' perspectives. By using the ICF in this context, the results will be comparable across studies, populations, and context, and enable clinicians to target treatment strategies for specific functional problems and to develop rehabilitation services to improve patient outcomes.

Therefore, the aim of this study was to describe commonly reported self-determined functional problems in Norwegian patients with neck pain and evaluate how they fit the ICF framework.

\section{Methods}

\section{Study design and participants}

This study was based on cross-sectional data collected from patients with neck pain referred to the neck and back outpatient clinic at Oslo University Hospital over a two-year period from December 2007 to December 2009. According to the quality register at the hospital, the referred patients had equal gender distribution and mean age of approximately 45 years.

The inclusion criteria were: age 16 years or older, presence of neck pain, and ability to communicate in Norwegian. According to the Bone and Joint Decade 2000-2010 Task Force on Neck Pain and Its Associated Disorders, ${ }^{16}$ and a new classification system for patients with neck pain seeking clinical care, we included patients who could be categorized into grade 2 (no structural pathology, but significant disability) or grade 3 (significant disability, and structural pathology). The exclusion criterion was a categorization as grade 4 (neck fractures, inflammatory rheumatic diseases, and systemic diseases causing neck pain). We chose broader classification criteria for neck pain due to the existing evidence that prognosis and treatment strategies are not strongly related to the specific findings in the neck. ${ }^{17}$

Patients referred to the clinic received the questionnaires to complete before the consultation. Questionnaires were sent to 600 referred patients. Thirty per cent of patients could not complete the questionnaire due to language barriers and were excluded, and approximately $10 \%$ were excluded due 
to other exclusion criteria. Of the 360 eligible patients, 30\% did not consent, giving an inclusion rate of $70 \%$.

The Patient-Specific Functional Scale ${ }^{9}$ is a self-determined measure of function that can be used in patients with musculoskeletal pain and varying levels of independence. The PSFS has been found to have good reliability, validity, and responsiveness for patients with neck disabilities. ${ }^{10}$ The extent to which PSFS items reflect ICF domains in patients with musculoskeletal pain has also been investigated. ${ }^{13}$ Patients in our study were asked to identify the three most important activities they were finding difficult to perform because of their neck pain. They were also asked to rate the strongest pain intensity experienced in the previous week using a numeric rating scale ranging from 1 ("no pain") to 10 ("the worst pain imaginable").

Written informed consent was obtained from the participating patients. The Regional Committee for Medical Research Ethics in the Health Region South-East approved the study.

\section{Data analysis}

The ICF was applied as a tool for analysis. Each ICF component consists of various domains, and each domain has specific categories, which are the units of the ICF classification. ${ }^{11}$ An example selected from the "activities and participation" component (d) could result in the domain "mobility" d4 (the first-level classification), with d415 "maintaining a body position" at the second level, and d4153 "maintaining sitting" at the third level. Established linking rules were used to guide the linking of functional problems to the ICF. ${ }^{18}$ Meaningful concepts within the functional problems nominated by each patient on the PSFS were identified, coded within the first and second levels of the classification, and linked to the components of body functions, and activities and participation. If the patients reported different problems in the same PSFS item, different meaningful concepts were identified in that item. For example, if patients noted, "I have headache when moving the neck", two concepts "headache" and "neck movement" were identified and linked to the separate ICF categories. If the meaningful concept could not be linked, this concept was assigned a "nondefinable" code (nd).

To increase the validity of the results, two researchers (NA and CR) performed coding and linking procedures independently. High correlations $(r=0.88-0.91)$ between researchers in linking to the ICF and good reliability (Cronbach's alpha $=0.91-0.97$ ) were found. However, in cases of disagreement, we established agreement through a consensus meeting. ICF categories were presented by percentage of the total number of functional problems linked to the ICF. The categories linking to $10 \%$ (or more) of problems were regarded as more frequent, and those linking to fewer than $10 \%$ were regarded as less frequent, in line with prior study. ${ }^{8}$

The characteristics of the participants were reported as percentage of included patients, means and standard deviations (SD), median and interquartile ranges (IQR) or ranges.

\section{Results}

The mean age of the 249 participants was 45.7 years (SD 11.7). The characteristics of the participants are summarized in Table 1. The majority of the patients suffered from chronic neck pain $(96 \%)$, with a mean pain intensity of 7.3 as indicated on the numeric rating scale. At the assessment time, $56 \%$ of the patients were on sick leave.

Of 628 reported functional problems by the PSFS, 13 meaningful ICF domains were identified: four domains loading on a body functions component (b) and nine domains loading on the activities and participation component (d).

Of the twelve categories referring to body functions, four were in the domain of mental functions (b1), followed by three categories in the neuromusculoskeletal and movement-related

Table I Characteristics of participants $(\mathrm{N}=249)$

\begin{tabular}{|c|c|}
\hline Variables & $\begin{array}{l}\text { Values } \\
\text { (\% of total N) }\end{array}$ \\
\hline Female & 45 \\
\hline Male & 55 \\
\hline Age (years)* & 45.7 (II.7) \\
\hline \multicolumn{2}{|l|}{ Marital status } \\
\hline Living with someone (married/partnership) & 68 \\
\hline Living alone (unmarried/widowed/divorced) & 32 \\
\hline \multicolumn{2}{|l|}{ Education } \\
\hline $0-12$ years & 63 \\
\hline$\geq 13$ years & 37 \\
\hline \multicolumn{2}{|l|}{ Work activity } \\
\hline \multicolumn{2}{|l|}{ Demands } \\
\hline Blue collar & 23 \\
\hline White collar & 76 \\
\hline \multicolumn{2}{|l|}{ Work ability } \\
\hline Full-time job/part-time job & 31 \\
\hline Sick leave & 56 \\
\hline Other & 13 \\
\hline Sick leave (weeks) ${ }^{* *}$ & $13(7.0-36.5)$ \\
\hline \multicolumn{2}{|l|}{ Duration of neck pain } \\
\hline$<3$ months & 4 \\
\hline$>3$ months & 96 \\
\hline Pain intensity on NRS ${ }^{+* *}$ & $7.3(2.05)$ \\
\hline
\end{tabular}

Notes: *Expressed as mean (SD); **expressed as median (IQR); ${ }^{\dagger}$ values ranging from I ("no pain") to 10 ("the worst pain imaginable").

Abbreviations: SD, standard deviation; IQR, interquartile range; NRS, numeric rating scale. 
functions domain (b7). The fewest categories were in the genitourinary and reproductive functions domain (b6) (Table 2).

Of the 31 categories referring to activities and participation, nine were in the mobility domain (d4), followed by four in the self-care domain (d5). The fewest links were in the communication domain (d3) (Table 3 ).

Within the 88 second-level ICF classification categories of body functions, the most frequently reported items were sleep function (b134; 27\%) and mobility of joint functions (b710; 26\%).

Within the 538 second-level categories of activities and participation, remunerative employment (d850; 15\%) was reported as the most frequent item, closely followed by doing housework (d640; 14\%), and recreation and leisure activities (d920; 13\%). Lifting and carrying objects (d430) was also frequently reported (10\%), while driving (d475) and maintaining a body position (d415) were reported in less than $10 \%$ of problems (see Table 3 ).

Only two meaningful concepts described as "be active" and "to function after activities" were not assigned to a specific ICF category. These were reported by one patient each, and coded as nondefinable (nd).

\section{Discussion}

An assessment of the self-reported functional problems in patients with neck pain showed that the majority of specific

Table 2 Percentage of self-determined functional problems on PSFS linked to the ICF component of body functions $(N=88)$

\begin{tabular}{ll}
\hline ICF domains and categories & $\begin{array}{l}\text { Percentage of reported } \\
\text { body functions problems } \\
\text { (\%) }\end{array}$
\end{tabular}

\begin{tabular}{ll}
\hline Mental functions (b I) & \\
bI30 Energy and drive functions & 4.5 \\
b134 Sleep functions & 27.2 \\
bI40 Attention functions & 9.2 \\
b164 Higher-level cognitive functions & 3.4 \\
Sensory functions and pain (b2) & \\
b240 Dizziness & 2.3 \\
b265 Touch function & 3.4 \\
b280 Sensation of pain & 6.7 \\
Genitourinary and reproductive functions (b6) \\
b640 Sexual functions & 3.4 \\
Neuromusculoskeletal and movement-related functions (b7) \\
b7I0 Mobility of joint functions & 26.2 \\
b730 Muscle power functions & 5.7 \\
b735 Muscle tone functions & 2.3 \\
b760 Control of voluntary movement & 5.7 \\
$\quad$ functions & \\
\hline
\end{tabular}

Abbreviations: PSFS, Patient-Specific Functional Scale; ICF, International Classification of Functioning, Disability, and Health.
Table 3 Percentage of self-determined functional problems on PSFS linked to the ICF component of activities and participation $(\mathrm{N}=538)$ \begin{tabular}{ll}
\hline ICF domains and categories & $\begin{array}{l}\text { Percentage of reported activities } \\
\text { and participation problems }\end{array}$
\end{tabular}

(\%)

Learning and applying knowledge (d I)

dI55 Acquiring skills $\quad 0.2$

dI60 Focusing attention $\quad 0.4$

dI66 Reading $\quad 4.0$

dI70 Writing 0.6

General tasks and demands (d2)

d220 Undertaking multiple tasks 0.4

d230 Carrying out daily routine $\quad 0.6$

d240 Handling stress and other $\quad 0.4$ psychological demands

Communication (d3)

d360 Using communication $\quad 5.0$ devices and techniques

Mobility (d4)

d410 Changing body position $\quad 1.0$

d4I5 Maintaining a body position 7.8

d420 Transferring oneself $\quad 0.4$

d430 Lifting and carrying objects $\quad 10.4$

d440 Fine hand use $\quad 0.6$

d445 Hand and arm use $\quad 2.4$

d450 Walking 3.1

d455 Moving around $\quad 3.0$

d475 Driving $\quad 9.0$

Self-care (d5)

d510 Self-washing $\quad 1.0$

d520 Caring for body parts $\quad 1.0$

d540 Dressing $\quad 1.5$

d570 Looking after one's health $\quad 0.6$

Domestic life (d6)

d630 Preparing meals $\quad 0.4$

d640 Doing housework $\quad 14.0$

d660 Assisting others $\quad 0.8$

Interpersonal interactions and relationship (d7)

d750 Informal social relationship $\quad 1.5$

d760 Family relationship $\quad 1.0$

Major life area (d8)

d839 Education 0.6

d850 Remunerative employment $\quad 14.7$

d855 Non-remunerative $\quad 0.2$

employment

Community, social and civic life (d9)

d920 Recreation and leisure $\quad 13.2$

d930 Religion and leisure $\quad 0.2$

Abbreviations: PSFS, Patient-Specific Functional Scale; ICF, International Classification of Functioning, Disability, and Health.

functional problems presented in this study fit with the ICF model.

By dividing the linked categories into more and less frequently reported, we were able to highlight the typical functional problems described by these patients. Problems with functions belonging to the activities and participation 
component were the most frequently reported and in accordance with findings in a study from New Zealand. ${ }^{13}$ However, the study found that patients with neck problems showed a higher proportion of body function impairments than those reported by patients with musculoskeletal pain in other body regions. ${ }^{13}$

Sleep disturbance was a frequently reported body function problem in our study. According to Sjors et al, ${ }^{19}$ it has been suggested that neurobiological sensitization at the somatic, cognitive, and behavioral level may increase the prevalence of sleeping problems. ${ }^{19}$ Another possible explanation is that sleeping problems are secondary to the consequences of living with chronic pain. ${ }^{20}$

Functional problems with mobility of joint functions were also frequently described. The cervical range of motion is often used in clinical practice as a functional outcome measure. ${ }^{21}$ Previous studies have reported that patients with subclinical neck pain showed important signs of impairment in neck muscle endurance, rotation, and extension movement. ${ }^{22,23}$ These impairments in range of motion and muscle endurance may be early physical markers of the development of chronic neck pain. ${ }^{23}$ Other studies have reported that rotation and extension in the cervical spine are commonly reduced in chronic neck pain patients. ${ }^{22}$

The substantial number of links to the activities and participation categories supports the evidence that currently exists. ${ }^{13}$ Patients reported problems with static activities such as, computer work (ie, category of using communication devices and techniques), driving and maintaining a body position (ie, sedentary activities), and lifting and carrying objects. Neck pain is linked to movement repetitions, awkward postures and prolonged maintenance of static postures. $^{21,24}$ Sustained static muscle activation has also been associated with chronic neck pain. ${ }^{25}$ For example, the progressive deterioration in the posture of computer workers has been associated with an increase in trapezius muscle activity while performing data entry tasks. ${ }^{26}$

Functional problems, including housework, recreation and leisure, and employment, were the main areas of limitation in the component of activities and participation. Housework activities, such as cleaning, and problems with an active life style, including regularly training, swimming, and bicycling, were also noted. It has been reported that nonspecific neck pain impacted on the risk of limited physical and social functioning in the long-term perspective. ${ }^{27}$ Our findings of frequently reported problems regarding employment may reflect the fact that almost $60 \%$ of patients were on long-term sick leave at the time of the assessment. The mean age of patients showed that they were in their most productive years, in accordance with previous studies. ${ }^{28}$ According to a recently published review article, neck disorders are a significant source of activity limitations in workers. The complex relationships between individual and workplace risk factors, such as occupation, poor job satisfaction, awkward work postures, poor physical work environment, emotional problems, and workers' ethnicity, may be associated with neck pain. ${ }^{29}$

A study by Ferreira et al, ${ }^{14}$ found that the most frequently used measurement of neck pain-related disability with predetermined items, the Neck Disability Index (NDI), ${ }^{30}$ demonstrated a well-balanced distribution of items across the ICF components. The NDI contains the following items: pain intensity, personal care, lifting, reading, headache, concentration, work, driving, sleeping, and recreational activities.

The findings in our study were comparable with Ferreira's findings regarding the distribution of self-determined functional problems and NDI items. ${ }^{14}$ However, frequently reported functions and activities in our study, such as mobility of joint functions, maintaining a body position, using communication devices and techniques, and doing housework, are not part of the NDI. Additionally, a number of functions reported with low frequency in our study, such as several categories of general tasks and demands (including psychological demands) and interpersonal interactions and relationship, are not included in the NDI. Taken together, the most and least frequently reported functions in our study seem to provide significant knowledge about the self-determined functional consequences of chronic neck pain. The use of the PSFS as a supplement to NDI assessment may enable clinicians to obtain a more complete picture of neck pain-related functional limitations and patient needs.

From the ICF perspective, the ICF-based "Core Sets" for the classification of health conditions have been developed. ${ }^{31}$ These core sets select a subset of categories that can serve as minimal standards for the assessment of functioning and health in relation to specific disorders including arthritis, low back pain, and other chronic musculoskeletal conditions. ${ }^{32}$ As there is currently no core set for neck pain, we chose to utilize the patient's own experience to classify their functional problems and linked those to the ICF. The results of this study may contribute to the identification of the aspects of functioning that need to be addressed in the clinical assessment, evaluation, and rehabilitation of patients with neck pain.

Some study limitations should be mentioned. The patients were recruited from a university hospital and represent a 
sample with long-lasting disability related to neck pain. Half of the invited patients were not eligible for the study due to exclusion criteria, giving a low response rate. However, we included $70 \%$ of all eligible patients. Their gender distribution and mean age was equal to that of other patients with neck pain referred to the clinic (source: quality register at the hospital), making the study results generalizable. The complete health experience of a person with neck pain was not widely described in this study as the PSFS failed to represent the context of personal and environmental factors, and the study was not designed to assess the influence of psychological distress on neck pain-related disability.

\section{Conclusion}

The majority of the specific functional problems presented by patients in this study showed a good fit with the ICF model. By dividing the linked categories into more and less frequently reported functions, we were able to highlight typical functional problems in these patients that need to be addressed in the clinical assessment. The frequent links to the body functions categories (ie, sleep function and mobility of joints) and to the activities and participation categories (ie, lifting and carrying objects, doing housework, employment, recreation and leisure) indicate a multidimensionality of functional problems. Interventions designed to improve functional status of patients with neck pain-related disability should integrate these complexities as well as include a multidisciplinary rehabilitation team in order to secure best functional outcomes for patients.

\section{Disclosure}

The authors declare they have no conflicts of interest.

\section{References}

1. Kuorinka I, Jonsson B, Kilbom A, et al. Standardised Nordic questionnaires for the analysis of musculoskeletal symptoms. Appl Ergon. 1987;18(3):233-237.

2. Carroll LJ, Hurwitz EL, Côté P, et al. Research priorities and methodological implications: the Bone and Joint Decade 2000-2010 Task Force on Neck Pain and Its Associated Disorders. J Manipulative Physiol Ther. 2009;32(Suppl 2):S244-S251.

3. Feleus A, Bierma-Zeinstra SM, Miedema HS, Bernsen RM, Verhaar JA, Koes BW. Incidence of non-traumatic complaints of arm, neck and shoulder in general practice. Man Ther. 2008;13(5):426-433.

4. Hill J, Lewis M, Papageorgiou AC, Dziedzic K, Croft P. Predicting persistent neck pain: a 1-year follow-up of a population cohort. Spine (Phila Pa 1976). 2004;29(15):1648-1654.

5. Borghouts JA, Koes BW, Bouter LM. The clinical course and prognostic factors of non-specific neck pain: a systematic review. Pain. 1998;77(1):1-13.

6. Hansson EK, Hansson TH. The costs for persons sick-listed more than one month because of low back or neck problems. A two-year prospective study of Swedish patients. Eur Spine J. 2005;14(4):337-345.
7. Barten JA, Pisters MF, Huisman PA, Takken T, Veenhof C. Measurement properties of patient-specific instruments measuring physical function. J Clin Epidemiol. 2012;65(6):590-601.

8. Tschiesner U, Linseisen E, Baumann S, et al. Assessment of functioning in patients with head and neck cancer according to the International Classification of Functioning, Disability, and Health (ICF): a multicenter study. Laryngoscope. 2009;119(5):915-923.

9. Stratford P, Gill C, Westaway M, Binkley J. Assessing disability and change on individual patients: a report of a patient specific measure. Physiother Can. 1995;47(4):258-263.

10. Westaway MD, Stratford PW, Binkley JM. The patient-specific functional scale: validation of its use in persons with neck dysfunction. J Orthop Sports Phys Ther. 1998;27(5):331-338.

11. WHO. The International Classification of Functioning, Disability and Health-ICF. Geneva: World Health Organization [2001]. Available from: http://www.who.int/classifications/icf/en/. Accessed September 6, 2012.

12. Wade DT, de Jong BA. Recent advances in rehabilitation. $B M J$. 2000;320(7246):1385-1388.

13. Fairbairn K, May K, Yang Y, Balasundar S, Hefford C, Abbott JH. Mapping Patient-Specific Functional Scale (PSFS) items to the International Classification of Functioning, Disability and Health (ICF). Phys Ther. 2012;92(2):310-317.

14. Ferreira ML, Borges BM, Rezende IL, et al. Are neck pain scales and questionnaires compatible with the international classification of functioning, disability and health? A systematic review. Disabil Rehabil. 2010;32(19):1539-1546.

15. Lee KC, Chiu TT, Lam TH. The role of fear-avoidance beliefs in patients with neck pain: relationships with current and future disability and work capacity. Clin Rehabil. 2007;21(9):812-821.

16. Haldeman S, Carroll L, Cassidy JD, Schubert J, Nygren A; for The Bone and Joint Decade 2000-2010 Task Force on Neck Pain and Its Associated Disorders. The Bone and Joint Decade 2000-2010 Task Force on Neck Pain and Its Associated Disorders: executive summary. Spine (Phila Pa 1976). February 15, 2008;33(Suppl 4):S5-S7.

17. Carroll LJ, Hogg-Johnson S, van der Velde G, et al. Course and prognostic factors for neck pain in the general population: results of the Bone and Joint Decade 2000-2010 Task Force on Neck Pain and Its Associated Disorders. J Manipulative Physiol Ther. 2009;32(Suppl 2):S87-S96.

18. Cieza A, Geyh S, Chatterji S, Kostanjsek N, Ustün B, Stucki G. ICF linking rules: an update based on lessons learned. J Rehabil Med. 2005;37(4): 212-218.

19. Sjörs A, Larsson B, Persson AL, Gerdle B. An increased response to experimental muscle pain is related to psychological status in women with chronic non-traumatic neck-shoulder pain. BMC Musculoskelet Disord. 2011;12:230.

20. Eriksen HR, Ursin H. Sensitization and subjective health complaints. Scand J Psychol. 2002;43(2):189-196.

21. Howell ER. The association between neck pain, the Neck Disability Index and cervical ranges of motion: a narrative review. J Can Chiropr Assoc. 2011;55(3):211-221.

22. Jordan A, Mehlsen J, Ostergaard K. A comparison of physical characteristics between patients seeking treatment for neck pain and age-matched healthy people. J Manipulative Physiol Ther. 1997;20(7):468-475.

23. Lee H, Nicholson LL, Adams RD. Cervical range of motion associations with subclinical neck pain. Spine (Phila Pa 1976). 2004;29(1):33-40.

24. Madeleine P, Lundager B, Voigt M, Arendt-Nielsen L. Shoulder muscle co-ordination during chronic and acute experimental neck-shoulder pain. An occupational pain study. Eur J Appl Physiol Occup Physiol. 1999;79(2):127-140.

25. McLean L. The effect of postural correction on muscle activation amplitudes recorded from the cervicobrachial region. J Electromyogr Kinesiol. 2005;15(6):527-535.

26. Kleine BU, Schumann NP, Bradl I, Grieshaber R, Scholle HC. Surface EMG of shoulder and back muscles and posture analysis in secretaries typing at visual display units. Int Arch Occup Environ Health. 1999;72(6):387-394. 
27. Thelin A, Holmberg S, Thelin N. Functioning in neck and low back pain from a 12-year perspective: a prospective population-based study. J Rehabil Med. 2008;40(7):555-561.

28. Lakke SE, Soer R, Takken T, Reneman MF. Risk and prognostic factors for non-specific musculoskeletal pain: a synthesis of evidence from systematic reviews classified into ICF dimensions. Pain. 2009; 147(1-3):153-164.

29. Côté P, van der Velde G, Cassidy JD, et al. The burden and determinants of neck pain in workers: results of the Bone and Joint Decade 2000-2010 Task Force on Neck Pain and Its Associated Disorders. J Manipulative Physiol Ther. 2009;32(Suppl 2):S70-S86.
30. Vernon H, Mior S. The Neck Disability Index: a study of reliability and validity. J Manipulative Physiol Ther. 1991;14(7):409-415.

31. Stucki G, Kostanjsek N, Ustün B, Cieza A. ICF-based classification and measurement of functioning. Eur J Phys Rehabil Med. 2008;44(3): 315-328.

32. Schwarzkopf SR, Ewert T, Dreinhöfer KE, Cieza A, Stucki G. Towards an ICF Core Set for chronic musculoskeletal conditions: commonalities across ICF Core Sets for osteoarthritis, rheumatoid arthritis, osteoporosis, low back pain and chronic widespread pain. Clin Rheumatol. 2008;27(11):1355-1361.

\section{Publish your work in this journal}

Patient Preference and Adherence is an international, peer-reviewed, open access journal focusing on the growing importance of patient preference and adherence throughout the therapeutic continuum. Patient satisfaction, acceptability, quality of life, compliance, persistence and their role in developing new therapeutic modalities and compounds to optimize clinical outcomes for existing disease states are major areas of interest. This journal has been accepted for indexing on PubMed Central. The manuscript management system is completely online and includes a very quick and fair peer-review system. Visit http://www.dovepress.com/ testimonials.php to read real quotes from published authors.

Submit your manuscript here: http://www.dovepress.com/patient-preference-and-adherence-journal 